\title{
Shape of Life: A Qualitative Study on the Challenges Posed by Diabetic Students
}

\author{
Julius A. Reyes, Ed.D. ${ }^{1,2,3}$, Jacob Cyril C. Burog ${ }^{1,2,3}$, Patrick Lawrence S. Gomez \\ 1,2,3, Kyle Dominic R. Reantoquio ${ }^{1,2,3}$, Angel Rae C. Bartolome 1,2,3, Christina Ricci \\ O. Bernados ${ }^{1,2,3}$, Khuzyma S. Blin ${ }^{1,2,3}$, Katrina M. Castroverde ${ }^{1,2,3}$, Keziah Mae A. \\ Gonzalvo ${ }^{1,2,3}$
}

${ }^{1}$ Philippine School Doha, Doha, Qatar ${ }^{2}$ Research Development, Accreditation and Publication Office, PSD, Doha, Qatar

${ }^{3}$ Research Capstone Project, PSD, Doha, Qatar

\begin{abstract}
Background: Diabetes is a prominent disease that affects people of all ages. Having diabetes requires extensive care from the affected patient and this is especially hard for those of younger ages. Particularly, students have a difficult time dealing with their medical condition because not only do they have to deal with responsibilities in school, but they also have to manage their medical condition. Method: This qualitative study will utilize the phenomenological research design which aims to understand the lived experiences and behavior of diabetic students, relative to the central question: "What are the common problems of students with diabetes with regard to their stay in the State of Qatar?" Data were collected through a twenty-five semi-structured interview, and were analyzed utilizing an inductive approach in theme development. Findings: Findings have shown the common challenges of diabetic students as they study here in Qatar and the different aspects of their life affected by their medical condition. Conclusion: The challenges and experiences that students experience is extensive as the level of acceptance of each respondent also differs. Recommendation: In order to fill in the literature gap, this paper suggests future researchers to explore deeper into other challenges of diabetic students, such as academic challenges.
\end{abstract}

Published by IJRP.ORG. Selection and/or peer-review under responsibility of International Journal of Research Publications (IJRP.ORG)

Keywords: Diabetic Students; Type 1 Diabetes; Challenges of Diabetiic Students; Lifestyle; Diabetes Distress

\section{Introduction}

Diabetes is a condition that affects how a person's body uses blood sugar. It can take a toll on the body of a diabetic patient, especially if left unmanaged. It can cause many problems that can range from losing concentration to affecting major organs in the body or even causing death. This is a concerning problem for most patients, especially those who get diagnosed at a young age. They are now faced with numerous responsibilities to keep their health condition in check.

Some patients develop Type 1 diabetes (T1D), particularly during childhood to young adulthood, and have 
difficulty dealing with their medical condition. Being diagnosed with T1D at an early age may also be hard to accept for some adolescents because they are in a life period that incorporates a host of challenges and changes (Masten, Obradović, \& Burt, 2006; as cited in Tetzner et al., 2017). Meanwhile, young adults with T1D face developmental milestones and are also expected to take full responsibility for managing their medical condition (Bronner et al., 2020). Many patients find handling T1D difficult and demanding, and it can greatly affect their everyday life and social activities ("Exploring the Effects of being Diagnosed with Type 1 Diabetes", 2020). Factoring in the difficulties of managing diabetes, a diabetic adolescent might find it stressful juggling different responsibilities simultaneously.

Students diagnosed with T1D encounter various challenges that necessitate them to adapt and adjust their lifestyle to cope with their medical condition. School-life components such as academics, sleep, nutrition, physical activity, mental health, and support systems are the common areas where a diabetic student has to adjust (Saylor \& Calamaro, 2016). These components can be narrowed down to 3 main challenges. The focus was to discuss these challenges that affect a student's everyday experiences. Diabetic students are faced with struggles of different facets related to health, personal emotions, and family. A diabetic adolescent may also experience diabetes distress caused by various stressors such as dietary and parent-related distress (Hagger et al., 2016). Although most of the focus has been placed on physical challenges, acknowledging the psychological impact of diabetes is also essential for proper disease management (Rariden, 2019).

The research paper discussed the shifts in the life of diabetic students in Qatar as they were diagnosed with diabetes and the challenges they were going through while living with it. Such topics included changes in diet and lifestyle, struggles encountered during studies, and relationships with other people. The researchers pursued this topic to know the lived experiences of diabetic students in Qatar, which made this study significant for them and those who will read it.

Readers can use this paper as a guide and insight on how diabetic students lead their lives and what they went through in the duration of having the illness. One must understand these students' lifestyles and situations to interact and communicate with them properly. Through this paper, readers, along with teachers and colleagues, can achieve that. Diabetic students who are unfamiliar with their medical condition can also utilize this paper as an insight to know how those with similar conditions cope with the difficulties and challenges they encounter in their daily lives.

This study utilized the qualitative method and used the phenomenological research design to be able to collect results. It focuses on the in-depth experiences as vocalized by the participants through interviews rather than observing behavior and measuring occurrences. The researchers investigated these experiences to discern the experiences, reactions, and emotions of the individuals to comprehend the occurrences about the lived experiences of students with diabetes.

\section{Method}

\subsection{Research Design}

This study utilized a qualitative method. The type of research design used is the Phenomenology research design to gather results and understand the respondents' lived experiences and human behaviors in the study. Qualitative research is an approach that allowed researchers to examine people's experiences in detail by using a specific set of research methods. Qualitative research is conducted to understand behavior, beliefs, opinions, and emotions from the perspective of study participants themselves. (Hennick, Hutter, \& Bailey, 2011; as cited in White, 2016). Phenomenology, the study of an individual's lived experience, aims to gather 
a deeper understanding of the nature and meaning of everyday experiences (Van Manen 1900; as cited in Derico, 2017).

\subsection{Research Locus and Sample}

The study was conducted at Philippine School Doha, a learning establishment in Qatar, providing fundamental teaching for the Filipinos. The Institute has been distinguished for its high-quality training and bequests to the Filipino communities in Qatar and the Philippines. It has performed as an emblem of distinction and success. PSD was selected due to the availability that it gave for the convenience and acquirable for the researchers. It provided an accessible place for the research advisor.

The researchers found five (5) participants who were diabetic students who lived in Qatar. The respondents' qualifications must be high school to college students ranging from 16-23 years old and can be of any nationality. The respondents were chosen according to the severity of their medical condition.

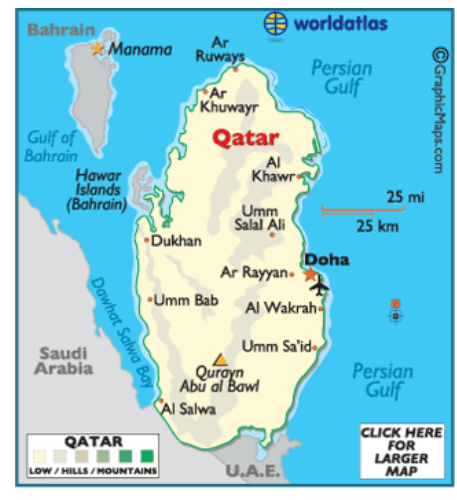

Figure 1: Map of Qatar $c c$ : WorldAtlas

https://www.worldatlas.com/we bimage/countrys/asia/qa.htm

\subsection{Data Collection and Ethical Consideration}

Before the interview proper, the respondents filled out two forms: the robotfoto and the consent letter. The robotfoto was utilized to obtain the respondents' demographic sketch, including their name, age, gender, school level, type of diabetes, contact number, e-mail address, nationality, and address. Subsequently, the consent letter was given to the respondents. This allowed the researchers to determine their preferred schedule to partake in the interview and inform the participants about the study's intentions. After filling out these forms, a twenty-five item semi-structured interview followed to discover the respondents' personal experiences, struggles, and feelings. It was conducted through the use of gadgets to communicate with them easily. The data gathered was transcribed verbatim and kept with the utmost confidentiality among the research committee (Guzman and Tan, 2007; as cited in Dipasupil et al., 2019).

\subsection{Mode of Analysis}

To analyze the findings thoroughly, the researchers opted to follow an inductive approach in theme development and to have the gathered data analyzed comprehensively by the researchers: (1) listening and relistening to the audio recordings to understand their perception about the topic further; (2) doing the emic transcription by transcribing the data obtained word-per-word; (3) transforming emic transcription to etic transcription which is the understanding of the researchers based on the participants' responses ; (4) organizing formulated meanings into categories, placing thought units, and cluster of themes via a dendrogram to show the similarities of the data (5) creating a simulacrum to serve as the visual representation of the findings (Ryan, 2003; as cited in Vallesteros, 2019). 


\section{Findings}

This phenomenological study details the lived experiences of diabetic students in the State of Qatar, relative to the central question: "What are the common problems of students with diabetes with regard to their stay in the State of Qatar?" Moreover, this study concentrated on the specific question: "What are the common school-related struggles of student expatriates who are suffering from diabetes?" The development of diabetes

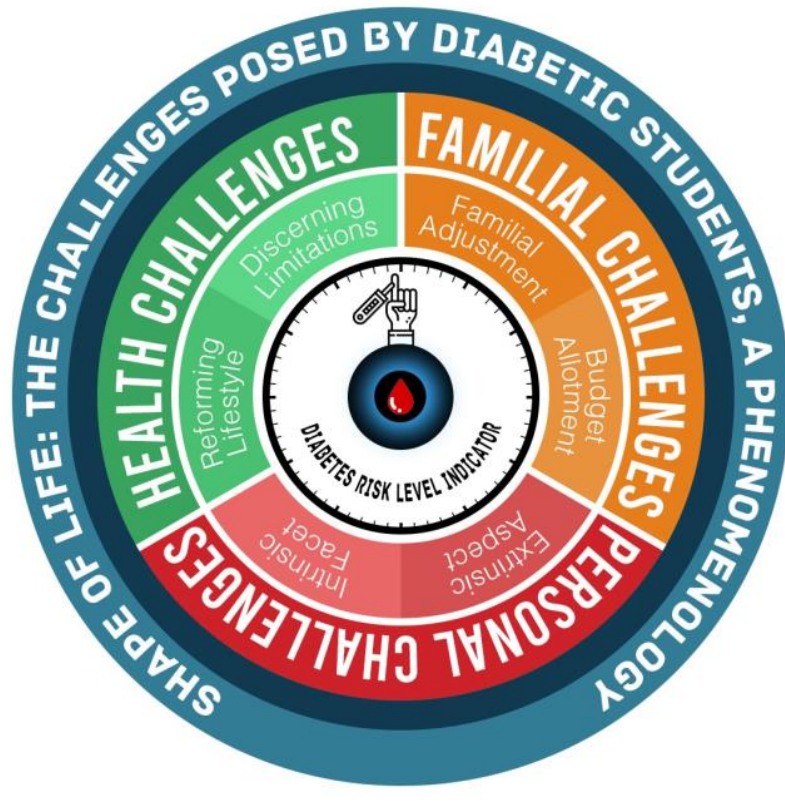

Figure 2: Simulacrum Common Challenges of Diabetic Students at young ages has many repercussions on the well-being of diabetic patients and is directly related to significant morbidity, mortality, and loss of economic productivity (Unnikrishnan, Shah, \& Mohan, 2016). Patients diagnosed with diabetes tend to be vulnerable to psychological instability and diabetes distress (Batool \& Sadiq, 2016).

Figure 2 shows the simulacrum focused on three major themes: health challenges, familial challenges, and personal challenges. The blue circle, being a universal symbol for diabetes, is utilized in various parts of the simulacrum. According to the International Diabetes Federation (2019), the symbol used the color blue to represent the sky while the circular shape signifies unity. A representation of a diabetes risk level indicator is also employed in the simulacrum using intuitive colors: the color green for normal, orange for moderate, and red for severe.

\section{Health Challenges}

Students who have diabetes face many struggles and challenges concerning their health. Their condition necessitates them to adjust many aspects of their life to manage their symptoms and prevent further complications. Diabetic students have to adapt to their medical condition by adjusting their diet, exercising more often, getting adequate sleep, and taking insulin shots to prevent their condition from worsening. The findings of this study further revealed the health challenges and struggles of Diabetic students. They stated:

"Since I started having diabetes, I started having more exercise and eating fewer sweets, chips, and fast food. Not cutting it off completely but just eating less."RI

"I tend to exercise, eat healthy food, and have adequate sleep. I would also take insulin, injections doses, and check my blood sugar." $R 2$

This kind of restrained lifestyle might be difficult to accept for some diabetic students because they might not enjoy the food that they were able to eat before. A student attested: 
"It was hard for me to embrace my health condition. Especially seeing my mother and sister eating delicious food while I am eating bland food and not being able to eat the food that I like. "R3

Moreover, these health challenges cause limitations to their experiences and choices in life. One may need to be more careful when it comes to doing sports not to affect blood glucose levels. There are also limitations when it comes to the choice of food to consume. A diabetic student needs to have a proper diet to lessen the risk of severe symptoms. These health challenges put limitations on things that would be considered normal for people without the condition.

"If you have Type-1 Diabetes, you tend not to perform prolonged vigorous activities, so I have limited choice when it comes to selecting clubs or doing sports activities. I have to choose activities that won't affect my blood sugar." R2

"My choices are always limited, and usually, I can't get what I want. For example, I want to eat outside, I'm not allowed to eat fast food or sweet food because my options are limited when I'm eating. " R5

Diabetic symptoms, such as the blurring of one's vision, affect a diabetic student's concentration. One may find it difficult to focus in class due to the fluctuations in blood sugar levels, affecting their school performance.

"It deeply affects it. There are times that I cannot concentrate when I'm experiencing Hypoglycemia. It means that I have a low blood sugar level, so I tend to feel numb, or my eyesight would become blurry, so there are times that I could not see the board properly and it's hard to understand and concentrate." R2

"When I'm nervous during exams, my hands start shaking because of my blood sugar and nerves, then I get dizzy and have difficulty concentrating on the exam. That results in a decrease in my blood sugar. In terms of non-academic concerns, I used to love playing basketball, but now I can't. My mom and doctor say I can't because they're afraid something will happen." $R 4$

"Sometimes it's hard because if my glucose is either high or low in the morning, it may be hard for me to focus on my lessons. " R1

"Sometimes, I cannot concentrate in classes because my sugar levels are either too high or too low, which causes my vision to blur. I need to take a break and eat something whenever my blood sugar is too low." R2

\section{Familial Challenges}

It is not only the students who adapt to a newer lifestyle when they get diagnosed with diabetes but also their families take part in changing their way of life. Most of the changes were toward the food they eat. This is called a familial adjustment, where the family adjusts with their diabetic child to a new manner of living. The students with diabetes pointed out how each of their family members alters how they choose what food to eat because they do not want them to feel left out during meals. Family members also adjusted to this new normal to encourage living a healthy lifestyle.

"For my family, we started eating healthier. Everyone in my family ate less fast food. Most of the foods in our house are healthy foods. " R1 
"Even they adjusted for what they are eating. What I am eating, they would follow and adjust so that I won't feel the only one in a proper diet. They are helping me adjust to a new lifestyle that I should've already done before." R5

The families of the diabetic students regard togetherness that if one of the members suffered an illness, everyone in the household did their best to adjust accordingly, not to let one feel dismayed because of their complications. This was shown as one of the students disclosed:

"They had to change their lifestyle too because they do not want to make me feel disheartened when they get to eat the foods that I cannot eat. Now they would buy vegetables, fruits, and some essential nutrients we can take. They also join me during my regular exercises to encourage me to do it." $R 2$

Economic burden can cause a series of effects on a family in terms of standard of living, financial security, and comfort of the entire family. Diabetes can put a family under a lot of stress, especially when a family is not well off and has to make certain adjustments to their daily spending.

Two students emphasized that their family had to make room in their budget for medical expenses such as insulin cases and injections. Additionally, their family either spent extra money or cut costs on their food as diet is an essential factor contributing to diabetes.

"The major changes my family made was when we spent a lot of money for my medical needs. We needed to buy injections, insulin cases, and there were many calls. It was really costly. There were also changes in the food that I ate." R3

"They stopped bringing sweets at the house first then slowly they brought it back little by little so I can get used to how much sweets I can take for a month. They also put aside money to purchase my insulin." R4

\section{Personal Challenges}

Diabetic students face their personal challenges with courage and patience. With that said, it is not an easy responsibility, no matter how long one has been experiencing this. The emotional impact of diabetes on their relationship with others is heavy. Having diabetes can affect one's personal life. Simply managing it is already giving stress. One factor is that they already have a big concern that they need to take care of, like checking their blood sugar level, diet, and medication. In addition to that, socializing with other people can put more stress on the diabetic student.

Unluckily, some students with diabetes are having problems socializing. Emotions such as jealousy and sadness are what the students feel. They feel jealous when their friends can do what they want to do, and they cannot do it because of their condition. They get upset that they have limitations in some cases, such as activities in school and hangouts with friends.

"I feel bad and a little jealous because my classmates were able to attend prom but I was in the hospital. Overall, I do feel left out sometimes." R3

"I get upset and a bit jealous of my friends. I remind myself why I'm not able to do school activities and that I have something they may not understand. Then I cope with it like every other teenager out there." $R 4$ 
"I do feel envious sometimes because they are able to do things I would not be able to do because of my condition." $R 5$

Some students who have diabetes feel that it is simpler not to share their condition with others since they worry that they may get judged and get special treatment. Diabetic students prefer to keep it to themselves for them not to be treated differently. They fear that sharing this might increase the judgment they receive from their friends.

"I do not want other people to find out about my condition because it made them change their perception of me. As long as they do not question me about it, I am usually quiet about my condition." R5

"When I get hurt, the thoughts stay in my mind until my blood sugar levels get high and I start to feel dizzy and that is when the complications start to come in." R3

"I felt really sad because I felt like I was excluded. I also felt that I can't do something about it because having diabetes is my own personal problem and I don't work like the rest of them so I just tend to accept what I am and consider myself as a norm for a Type 1 Diabetic person." $R 2$

\section{Discussion}

Affecting over 400 million people worldwide, the illness diabetes is a recognized global health challenge and the Arab world is not spared by this. For example, in the Eastern Mediterranean region countries, the ubiquity of this illness ranges from 3.5\% to as high as 30\% (Al-Thani et al., 2018). In a local context, Qatar has one of the highest prevalence estimates of diabetes (17\%) in the world (Taheri et al., 2020). Diabetes is one of the major public health problems in Qatar and was even recognized as one of the Qatar National Health Strategy's high-priority diseases for preventive healthcare (Al-Thani et al., 2019).

The high maintenance management of type 1 and type 2 diabetes can change the nature of one's social world and undermine the emotional support and efforts of support providers. People with diabetes are in need of support from sources such as, family, friends, romantic partners, and the health care team (Wiebe, Helgeson, \& Berg, 2016).

Most young adults experience various changes from childhood to adolescence such as lifestyle (e.g. education, occupation), health care, and relationships. Young adults with diabetes must find a way through these transitions while taking more responsibility for their diabetes care and overall well-being (Monaghan, Helgeson, \& Wiebe, 2015).

\section{Health Challenges}

Lifestyle is an important factor to consider when talking about glycemic control in both diabetic type 1 and 2 patients. Healthy lifestyle changes can help in managing and mitigating symptoms of diabetes. The therapeutic approach includes different courses of action that help people manage diabetes. These include insulin therapy, dietary management, awareness about the disease, the ability to self-apply insulin and selfmonitor glycemia, regular physical activity, and psychosocial support. (Sales-Silvia Helena et al., 2016). 
Dietary management is essential for diabetic students to prevent further complications of one's medical condition. Most people diagnosed with diabetes undergo nutrition therapy. This is the treatment of a medical condition through changes in diet, which plays an integral role in the management of diabetes (Yamada, Kabeya, \& Noto, 2018). Glycemic control, which includes self-monitoring of glucose level, is one way to manage one's diet. Poor glycemic control can lead to many complications; thus patients are encouraged to strive to achieve predefined glycemic goals (Eyob, Netere, \& Belachew, 2019).

Routinely physical activity plays an important part in managing T1D (Kennedy et al., 2018). It is recommended for patients with T1D to have regular physical activity because it improves metabolic control and lessens cardiovascular risk, in addition to the important effect of reducing the risk of chronic complications of this pathology (Sales-Silvia Helena et al., 2016). Meta-analyses have found that aerobic and strengthening exercise provide not only cardiovascular and musculoskeletal benefits but also reduction in A1c, total cholesterol, and triglycerides for youth with Type-1 Diabetes (Tully et al., 2016).

Managing diabetes during one's adolescence can be challenging. During childhood, the diabetic's parents had the primary responsibility in managing their child's condition, however during the adolescence stage, the child assumes an increased level of responsibility in managing their condition (Flora, Gameiro, 2016). The acceptance and acknowledgment of being diagnosed with T1D may be more difficult in adolescence than at other times in people's lives. Adolescence is a crucial developmental stage wherein adolescents commonly experience various challenges in life. Factoring in the multiple things to consider when managing diabetes, it can be overwhelming for adolescents and may lead to suboptimal management of their condition ("Exploring the Effects of being Diagnosed with Type 1 Diabetes," 2020).

Handling a chronic disease comes with facing certain limitations. Moderate - to high-intensity household activities were related to an increased risk of diabetes (Oh, 2020). Carbohydrate, fat, protein and overall calorie intake are some of the modifiable risk factors diabetic patients have to keep an eye on, making them more selective of their food choices. (Burns, 2017). Adequate self - management requires constant attention, including frequent blood glucose monitoring, regular insulin administration, and complicated daily decision making (Rechenberg et al., 2018).

\section{Familial Challenges}

It is vital not only patients to be involved but also parents to be educated about diabetes when accounting the importance of lifestyle. Education should include the guidance about a healthy lifestyle and how to improve the control of the glycemic level. This can favor their quality of life of the family especially after the discovery of diabetes in a family member (Sales-Silvia et al., 2016).

In a research done by Chang (2017), she inferred that "family support" was a crucial factor in the adolescent's decisions about diabetes self-management. Among her participants, the younger ones needed more family support such as food preparation and medical assistance. For some of her older participants, family support instead became a barrier rather than helpful. As the diabetic grows older, responsibility for diabetes care is gradually transmitted from parent to child. Parental support can also help diabetics as increased parental support can help facilitate the adolescent to take responsibility for diabetes management (Ouzouni et. al, 2018).

When partaken with others such as family members, the process of overcoming diabetes is simpler (Corbett \& Smith, 2020). Simple things such as fusing the normalization of diabetes in everyday life is important for 
adolescents and their families (Babler \& Strickland, 2015). Incorporating a healthy lifestyle, like eating a well-balanced diet and engaging in physical activity, into the family's habits is vital to adolescents aiming for adequate glycemic control (American Diabetes Association, 2016).

Positive effects on diabetes management are linked with parents who are engaging. (Zappas \& Granger, 2017). According to Totka, Snethen, and Cox (2020), relationships among the parents, youth, and family are influenced by the daily care demands since it is complex and continuous to manage diabetes in the adolescent's life.

Another important factor in diabetes management is the budget allotment the family gives to purchase the necessities for the adolescent with diabetes to cope with the disease. The expenses sustained in the management of the child's diabetes determines glycemic control, quality of living, mental and social welfare of the child and his/her family. This implies that economic impact is one of the main factors that comes to the family in managing the diabetes of a child. (Kulkarni et al., 2020). The cost of managing diabetes is crucial, such as food and fee-based physical activities, and may arise in an increased financial burden for the child and the family (Zappas \& Granger, 2017). For some adolescents and their families, adjustments in the budget can be difficult if they are already strained with financial pressures (Chang, 2017).

The funding for the medicaments is an obstacle for the families. The cost for the treatment of diabetes drains the family resources quickly and insufficient family income could worsen the circumstances (Sanjari et al., 2016).

\section{Personal Challenges}

Late pre-adulthood and developing adulthood might be particularly strenuous on the grounds because TID treatment is a complex statutory that is undertaken during this momentary time. To oversee TID viably, people must direct both themselves and their social connections. (Wiebe, Berg, Mello, \& Kelly, 2018)

Interviews with students living with T1D discussed disclosure and social support interactions at universities. Findings stress the need for young adults with T1D to scaffold the university transition as disclosure will generate successful social support (Habenicht, Gallagher, O’Keeffe, \& Creaven, 2018).

For patients, T1D is also difficult to control and can seriously impact their everyday lives and social activities. It can be especially difficult in adolescence to recognize and respond to a T1D diagnosis considering this is a critical developmental phase during which major physical, neurological, psychosocial, and emotional changes occur (Corbett, \& Smith, 2020). An assortment of psychosocial and conduct factors, for example, low social help, low conventional personal satisfaction, and challenges in overseeing diabetes are related to a high enthusiastic weight in type-1 diabetes (Joensen, Almdal, \& Willaing, 2016).

Students with T1D are faced with the difficult errand of incorporating diabetes into their character. This incorporation cycle, alluded to as ailment character, may assume a significant function in how youth with T1D adapt to regulating and disease explicit difficulties (Raymaekers, Prikken, Vanhalst, Moons, Goossens, et al., 2020). Several mentioned how they felt less "natural" with T1D. Females were more likely to share T1D information and to identify positive self-perception changes as a result of T1D (Commissariat, Kenowitz, Trast, Heptulla, \& Gonzalez, 2016). 
There were varieties in how students adapted to the condition. At the point when diabetes was not seen as a component of a person's self-personality, it was seen progressively contrarily (Commissariat et al., 2016).

Many adolescents with T1D face numerous obstacles that affect their relationship with others. They have a hard time accepting their disease and often choose to not tell it to others. There are social and developmental problems in puberty and young adulthood that can affect the treatment of T1D. Forming and gaining new relationships such as with schoolmates, friends, and peers creates an opportunity of not revealing their T1D status (Pihlaskari, et al., 2020). Children and their parents explained how their everyday lives were influenced by stigmatization and social restrictions as a result of fear of revealing the disease, which could affect their status in society. Lack of information and misunderstandings in society about T1D contribute to negative effects, such as poorer diabetes control (Elissa, Bratt, Axelsson, Khatib, \& Sparud-Lundin, 2017).

When you have T1D, managing it includes a complex treatment regimen and often leads to increased stress and mental health problems in young people and families as young people enter adolescence (Rumburg, 2020). Youths with lower fear had more prominent cover with their parents' organizations and more network individuals with whom they would not share their feelings and emotions. (Shah, Ersig, \& Paik, 2019).

Adolescents with T1D affect their attitudes toward managing their diabetes. Simply because they wanted to look good and likable, they pay more attention to their self-image, where they do not share their disease; instead, they just kept it to themselves. They fear to have complications such as experiencing dizziness and nausea whenever they have hypoglycemia (Gurkan \& Bahar, 2019).

\section{Conclusion}

Diabetes is among the recognized global public health issues. Qatar has one of the highest prevalence estimates of diabetes (17\%) in the world (Taheri et al., 2020). Understanding the disease can contribute to increasing awareness about this debilitating condition. (Zuercher \& Gopalan, 2018).

Growing up and living with diabetes takes plenty of adjustments, especially for adolescents (Schaffer, Norris, \& Gordon, 2020). A growing segment of the school - aged population is affected by diabetes. It is even one of the most common metabolic diseases in children worldwide. The United States Centers for Disease Control and Prevention (CDC) has data to suggest that 208,000 children and adolescents (under age 20) have diabetes. Although the disease itself can be difficult for anyone to manage, adolescents face unique, age - specific challenges. For instance, management of diabetes is imperative in school settings as adolescents spend up to 7 hours or longer each weekday at school (Kise, Hopkins, \& Burke, 2017). Diabetic students have to face a lot of adjustments and sacrifices, particularly in their lifestyle and limitations. They also face challenges within their family and self. Taking this into account, the researchers intend to understand the common problems faced by students with diabetes in Qatar. The researchers specifically aim to recognize their school-related challenges.

Students have to change their lifestyles drastically to adjust to their medical conditions. The students may have to adjust their diet because certain foods could aggravate their condition. Dietary management is very important for diabetics, which is why most people have to go through nutritional therapy (Yamada, Kabeya, $\&$ Noto, 2018). They also need to adjust by making lifestyle changes, such as getting enough sleep and taking medications. They also need to be more physically active as this is important in managing the condition's 
symptoms. (Kennedy, Narendran, Andrews, Daley, \& Greenfield, 2018). They must adapt to the symptoms that come with the condition, such as blurring one's vision, affecting their perception during classes. All of these changes require the diabetic's action in adapting to their condition to change their lifestyle.

The family helps the one who has diabetes to cope with their condition by adjusting to how a diabetic person's lifestyle should be. The family may have to focus on eating healthier meals to adjust to those who have the condition. The family also has to modify their budget allotment to provide for the medical needs of the diabetic family member. In some cases, despite full medication coverage, the remaining expenses for managing diabetes were often prohibitive (Kulhawy-Wibe et al., 2018). This makes it necessary for family members to aid in affording medicine for the child. This may burden the family's finances, and the lack of supplies needed for the condition may worsen the health status of the child (Cruz et al., 2018). Families may resort to methods that can ease the strain on their budget to adjust. For example, encouraging their children to enroll in subsidized-school-meal programs can also help alleviate pressure on the family budget. (Gucciardi et al., 2019). Children with diabetes are not the only one who finds it difficult to adjust and deal with the new way of life, their parents or guardians also find it challenging, that is why they both help one another adjust and keep up with the new lifestyle they have. Adjusting to the new lifestyle can put the family under a lot of pressure and stress, especially when the parents fail to address the diabetic children's needs to manage their condition properly. Management of children with type 1 diabetes is dynamic and complex (Xuereb \& Xuereb, 2017).

Students who have type 1 diabetes tend not to confess their disease to their friends for the reason that their relationship with them will change as well as how they would be seen and treated. They are contemplating whether they would be accepted by their peers and friends when they opened up about their disease. A diabetic person who used to be healthy felt like an outcast since no one wants to socialize with a person who has a disease. It leads them to have a negative self-image due to responses and attitudes that the people with who they socialize show. It strongly affects how they view themselves, which gives them the choice not to tell others about their condition. Since they are scared of not being treated equally like others, they pretend to be healthy and fine (Nishio \& Chujo, 2017).

Diabetic students may also suffer from diabetes distress, which can be defined as negative psychological reactions to emotional burdens from diabetes (Rariden, 2019). Those kids who are determined to have diabetes may be influenced negatively, as far as how they feel about themselves, their relationship with others, their eating, and actual exercises. (Xuereb \& Xuereb, 2017). Diabetes distress can also cause the person with diabetes to feel guilty because of the intrusiveness of their friends and family (Hagger et al., 2016). Most of the respondents have answered that their friends would always try to adjust to them because of their disease, which would make them feel bad since they can't do anything about it. However, they manage to adapt physically and emotionally to their environment as time goes by. Previous studies also reported that diabetes could be a limiting factor for socialization (Andrade \& Alves, 2018). Socializing with other people has been one of the most challenging experiences for them since there are some activities that they can't participate in, which would result in them not being able to interact with others.

Based on the simulacrum of the study, the researchers were able to identify three major themes: health challenges, familial challenges, and personal challenges. Common challenges, such as academic, social, and family-related problems, were discerned when conducting the study. The researchers also found out that each respondent's experiences were extensive and can differ depending on the respondent's level of acceptance. However, this study's notable limitations are the respondents' age range. The respondents selected were 
between 16 to 23 years of age, and their locality, as respondents from Qatar were only selected. As a result, the researchers recommend future researches to increase their number of respondents with a broader or narrower age range. Future researchers can also consider categorizing respondents based on their level of acceptance of their medical condition. Additionally, the researchers also recommend exploring other challenges faced by diabetic students, such as academic challenges and the like.

\section{Acknowledgements}

The researchers would like to express their gratitude to those kind hearts who assisted and supported the making of this study. The researchers wish to recognize the valuable aid of the following people:

Dr. Alexander S. Acosta and Dr. Noemi F. Formaran, for being an inspiration and also granting the researchers the opportunity to conduct this study.

Dr. Lorina Villanueva, for her thoughtful support in this research study. Ms. Maidie Acosta, the school librarian for allowing the researchers to gather needed references and information in order to sustain the idea of this study.

Dr. Fredelito Don John A. Vallesteros, for his unforgettable lessons and advice that served as an enlightenment to pave the path in making this research paper possible.

Dr. Julius A. Reyes for his unending patience and assistance that guided the researchers towards the completion of this study.

Our family for their continuous support and appreciation.

And most importantly, with all the glory and honor, the researchers would like to give all their thanks to the Almighty God, for He has given the researchers the time, wisdom, and opportunity to make this research possible.

\section{References}

Al-Thani, A.-A., Farghaly, A. H., Akram, H., Khalifa, S. E., Vinodson, B., Loares, A. M., \& Abou-Samra, A.-B. (2018). Public Awareness and Perceptions about Diabetes in the State of Qatar. Cureus. https://doi.org/10.7759/cureus.2671

Al-Thani, A.-A., Farghaly, A., Akram, H., Khalifa, S., Vinodson, B., Loares, A., \& Abou-Samra, A.-B. (2019). Knowledge and Perception of Diabetes and Available Services among Diabetic Patients in the State of Qatar. Central Asian Journal of Global Health, 8(1). https://doi.org/10.5195/cajgh.2019.333

American Diabetes Association. (2016). Standards of medical care in diabetes-2016 abridged for primary care providers. Clinical diabetes: a publication of the American Diabetes Association, 34(1), 3.

Andrade, C., \& Alves, C. (2018). Relationship between bullying and type 1 diabetes mellitus in children and adolescents: a systematic review. https://pubmed-ncbi-nlm-nih-gov.eres.qnl.qa/30391140/

Babler E, Strickland CJ (2015) Normalizing: adolescent experiences living with type 1 diabetes. Diabetes Educator. 41, 3, 351-360. doi: $10.1177 / 0145721715579108 \mathrm{~V}$

Batool, A., \& Sadiq, R. (2018). Comparison of diabetes related distress and psychological well-being among patients with type I and type II diabetes mellitus. Pakistan Journal of Medical Research, 57(4), 149-153. Retrieved from https://search-proquestcom.eres.qnl.qa/docview/2186951458?accountid=49936

Bronner, M. B., Peeters, M. A., Sattoe, J. N., \& Van Staa, A. (2020). The impact of health-related quality of life. Health and Quality of Life Outcomes, 18(1). https://doi.org/10.1186/s12955-020-01370-8 
Burns, E. V. (2017). Assessing diabetes knowledge related to healthy eating habits in freshman and sophomore college students (Order No. 10637917). Available from ProQuest Dissertations \& Theses Global. (1973130347). Retrieved from https://search-proquestcom.eres.qnl.qa/docview/1973130347?accountid=49936

Chang, N. T. (2017). Understanding barriers to self-management among latino adolescents with type 2 DM (Order No. 10286842). Available from ProQuest Central; ProQuest Dissertations \& Theses Global. (1928956857). Retrieved from https://search-proquestcom.eres.qnl.qa/docview/1928956857?accountid=49936

Commissariat, P. V., Kenowitz, J. R., Trast, J., Heptulla, R. A., \& Gonzalez, J. S. (2016). Developing a personal and social identity with type 1 diabetes during adolescence. Qualitative Health Research, 26(5), 672-684. doi:10.1177/1049732316628835

Cruz, D. S. M. da, Silva, K. de L., Souza, J. T. B. de, Nóbrega, M. M. L. da, Reichert, A. P. da S., Marques, D. K. A., \& Collet, N. (2018). Vivência de adolescentes com diabetes mellitus na perspectiva da ética da alteridade. Acta Paulista de Enfermagem, 31(2), 130-136. https://doi.org/10.1590/1982-0194201800020

Cruz DS, Silva KL, Souza JT, Nóbrega MM, Reichert AP, Marques DK, Collet N. (2018) Experiences of adolescents with diabetes mellitus from the perspective of the Ethics of Alterity. Acta Paul Enferm. 2018;31(2):130-6.

Derico, S. P. (2017). The use of phenomenology in nursing education. Nursing Education Perspectives, $38(6)$, E7-E11. doi:10.1097/01.nep.0000000000000216

Elissa, K., Bratt, E., Axelsson, A. B., Khatib, S., \& Sparud-Lundin, C. (2017). Societal norms and conditions and their influence on daily life in children with type 1 diabetes in the West Bank in Palestine. Journal of Pediatric Nursing, 33, 16-22. doi:10.1016/j.pedn.2016.12.005

Exploring the effects of being diagnosed with type 1 diabetes in adolescence. (2020). Nursing Standard (2014+), 35(7), 77-82. doi:http://dx.doi.org.eres.qnl.qa/10.7748/ns.2020.e11556

Eyob, A. G., Netere, A. K., \& Belachew, S. A. (2019). Glycemic control among diabetic patients in ethiopia: A systematic review and meta-analysis. PLoS One, 14(8) doi:http://dx.doi.org.eres.qnl.qa/10.1371/journal.pone.0221790

Flora, M., \& Gameiro, M. (2016). Self-care of adolescents with type 1 diabetes: responsibility for disease management/Autocuidado dos adolescentes com diabetes mellitus tipo 1: responsabilidade no controlo da doença/Autocuidado de los adolescentes con diabetes mellitus tipo 1: responsabilidad en el control de la enfermedad, 4(9). https://web.a.ebscohost.com/abstract?direct=true\&profile=ehost\&scope=site \&authtype=crawler\&jrnl=08740283\&AN=115850855 \&h=rMbw0G7TMZ3vvKMhdqiBaplXYlzThbdrFOmnBzv2YdJwXkyI\%2bwpa9EmJaEy\%2fiztsRDriLetDXhotU7KFxguVJA\%3d $\% 3 \mathrm{~d} \& \mathrm{crl}=\mathrm{c} \&$ resultNs=AdminWebAuth\&resultLocal=ErrCrlNotAuth\&crlhashurl=login.aspx $\% 3$ fdirect $\% 3 \mathrm{dtrue} \% 26 \mathrm{profile} \% 3 \mathrm{dehos}$ t\%26scope\%3dsite\%26authtype\%3dcrawler\%26jrn1\%3d08740283\%26AN\%3d115850855

Fredelito Don John A. Vallesteros, Ph.D. , Dela Cruz, Angelica, Delavin, Alexandra, Merced, Andrianna, Platitas, Allyza, Tubello, Jollienne. (2018). The Long Way Home: The Social Diagraming of Philippine School Doha Alumni in the Philippines. Retrieved from https://pdfs.semanticscholar.org/3489/ba433840e6edefcdb77777f1de171a70360a.pdf

Gennaro, S. (2017). Why Do I Do Research? Why Should You Do Research? Journal of Nursing Scholarship, 49(4), 359-359. doi:10.1111/jnu.12306

GÜRKAN, K. P., \& Bahar, Z. (2019). Living with diabetes. Journal of Nursing Research, Publish Ahead of Print. doi:10.1097/jnr.0000000000000349

Gucciardi, E., Yang, A., Cohen-Olivenstein, K., Parmentier, B., Wegener, J., \& Pais, V. (2019). Emerging practices supporting diabetes self-management among food insecure adults and families: A scoping review. PLOS ONE, 14(11), e0223998. https://doi.org/10.1371/journal.pone.0223998

Hagger, V., Hendrieckx, C., Sturt, J., Skinner, T. C., \& Speight, J. (2016). Diabetes Distress Among Adolescents with Type 1 Diabetes: A Systematic Review. Current Diabetes Reports, 16(1), 9. https://doi.org/10.1007/s11892-015-0694-2

International Diabetes Federation. (2019). Logo. Retrieved from https://www.idf.org/who-we-are/aboutidf/logo.html\#: :text=The\%20blue\%20circle\%20is\%20the, attention\%20of\%20the\%20general\%20public

Joensen, L. E., Almdal, T. P., \& Willaing, I. (2016). Associations between patient characteristics, social relations, diabetes management, quality of life, glycaemic control and emotional burden in type 1 diabetes. Primary Care Diabetes, 10(1), 41-50. doi:10.1016/j.pcd.2015.06.007

Kennedy, A., Narendran, P., Andrews, R. C., Daley, A., \& Greenfield, S. M. (2018). Attitudes and barriers to exercise in adults with a recent diagnosis of type 1 diabetes: A qualitative study of participants in the Exercise for Type 1 Diabetes (EXTOD) study. BMJ Open, 8(1), e017813. https://doi.org/10.1136/bmjopen-2017-017813

Kise, S. S., Hopkins, A., \& Burke, S. (2017). Improving School Experiences for Adolescents With Type 1 Diabetes. Journal of School Health, 87(5), 363-375. https://doi.org/10.1111/josh.12507

Kulhawy-Wibe, S., King-Shier, K. M., Barnabe, C., Manns, B. J., Hemmelgarn, B. R., \& Campbell, D. J. T. (2018). Exploring structural barriers to diabetes self-management in Alberta First Nations communities. Diabetology \& Metabolic Syndrome, $10(1)$, 87. https://doi.org/10.1186/s13098-018-0385-7

Kulkarni, P., Babu, P., Rashmi, N., Kumar, D., Murthy, N. (2020). "Does cost of care influence the glycemic control, psychosocial illness and quality of care among adolescents with type 1 diabetes?: A hospital based cross section study in Mysuru, Karnataka, Clinical Epidemiology and Global Health, Volume 8, Issue 3, Pages 879-883, ISSN 2213-3984, https://doi.org/10.1016/j.cegh.2020.02.016.

Making the LEAP and finding your feet: A qualitative study of disclosure and social support in university students with type 1 diabetes Andrea Ellen Habenicht, Stephen Gallagher, Mary-Claire O'Keeffe, Ann-Marie Creaven, 2018. (2018, November 11). Retrieved from https://journals.sagepub.com/doi/abs/10.1177/1359105318810875 
Monaghan, M., Helgeson, V., \& Wiebe, D. (2015). Type 1 Diabetes in Young Adulthood. Current Diabetes Reviews, 11(4), 239-250. https://doi.org/10.2174/1573399811666150421114957

Nishio, I., \& Chujo, M. (2017, September 15). Self-stigma of patients with type 1 diabetes and their coping strategies. Retrieved from https://www.ncbi.nlm.nih.gov/pmc/articles/PMC5611471/

Oh, H. S. (2020). Opposite effects of work-related physical activity and leisure-time physical activity on the risk of diabetes in korean adults. International Journal of Environmental Research and Public Health, 17(16), 5812. doi:http://dx.doi.org.eres.qnl.qa/10.3390/ijerph17165812

Ouzouni, A., Galli-Tsinopoulou, A., Kazakos, K., Dimopoulos, E., Kleisarchaki, A., Mouzaki, K., \& Lavdaniti, M. (2018). The Intervention of Parents in Supporting of Diabetes Type 1 in Adolescents, 30(2). https://www.ncbi.nlm.nih.gov/pmc/articles/PMC6029902/\#: :text=The\%20parental\%20intervention\%20in\%20children,\%25\%20of $\% 20$ patients\%20(3)

Pihlaskari, A. K., Anderson, B. J., Eshtehardi, S. S., McKinney, B. M., Marrero, D. G., Thompson, D., \& Hilliard, M. E. (2020). Diabetes disclosure strategies in adolescents and young adult with type 1 diabetes. Patient Education and Counseling, 103(1), 208-213. doi:10.1016/j.pec.2019.08.019

Rariden, C. (2019). Diabetes distress: Assessment and management of the emotional aspect of diabetes mellitus. The Journal for Nurse Practitioners, 15(9), 653-656. https://doi.org/10.1016/j.nurpra.2019.06.020

Raymaekers, K., Prikken, S., Vanhalst, J., Moons, P., Goossens, E., Oris, L., \& Luyckx, K. (2020). The Social Context and Illness Identity in Youth with Type 1 Diabetes: A Three-Wave Longitudinal Study. Journal of Youth and Adolescence, 49(2), 449-466.

Rechenberg, K., Grey, M., \& Sadler, L. (2018). "Anxiety and type 1 diabetes are like cousins": The experience of anxiety symptoms in youth with type 1 diabetes. Research in Nursing \& Health, 41(6), 544-554. doi:10.1002/nur.21913

Rumburg, T. M. (2020, February 26). Adaptation of a resilience-oriented stress management intervention for youth with type 1 diabetes. Retrieved from https://digitalcommons.pepperdine.edu/etd/1097/

Ryan, G. W., \& Bernard, H. R. (2016). Techniques to Identify Themes - Gery W. Ryan, H. Russell Bernard, 2003. Retrieved from https://journals.sagepub.com/doi/ 10.1177/1525822X02239569

Sales-Silvia Helena, D. P., Maria deFatima, S. G., Leticia, M. S., Negrato, C. A., \& Pereira Lauris, J. R. (2016). Lifestyle of patients with diabetes mellitus type 1: A systematic review. 21(4). DOI:10.1590/1413-81232015214.20242015

Sanjari, M., Mehrdad, N., \& Peyrovi, H. (2016). Managing children with diabetes within the family: living in the orbit of diabetes. Endocrine Abstracts. doi:10.1530/endoabs.41.gp107

Saylor, J., \& Calamaro, C. (2016). Transitioning young adults with type 1 diabetes to campus life. The Journal for Nurse Practitioners, 12(1), 41-46. https://doi.org/10.1016/j.nurpra.2015.09.010

Schaffer, R., Norris, A., \& Gordon, Lydia, RN,B.S.N., C.S.N. (2017). Communication, careful planning ensure students with diabetes can succeed at school. Endocrine Today, 15(7), 1,12-14. Retrieved from https://search-proquestcom.eres.qnl.qa/docview/1920026463?accountid=49936

Lisa L. Shah, Anne L. Ersig, Anthony Paik, 2019. (2019, July 29). Social network factors and anxiety among adolescents with type 1 diabetes and their parents. Retrieved from https://journals.sagepub.com/doi/abs/10.1177/1074840719863719

Taheri, S., Chagoury, O., Tourette, M., Skaroni, I., Othman, M., Bashir, M., Abou-Samra, A. B. (2020). Managing diabetes in Qatar during the COVID-19 pandemic. The Lancet Diabetes \& Endocrinology, 8(6), 473-474. https://doi.org/10.1016/s22138587(20)30154-6

Tetzner, J., Kliegl, R., Krahé, B., Busching, R., \& Esser, G. (2017). Developmental problems in adolescence: A person-centered analysis across time and domains. Journal of Applied Developmental Psychology, 53, 40. Retrieved from https://search-proquestcom.eres.qnl.qa/docview/2043315684?accountid=49936

Totka, J., Snethen, J., Cox, E. (2020) Youth and Parent Health-Related Quality of Life and Association With Glycemic Outcomes in Preadolescents and Adolescents With Type 1 Diabetes, Journal of Pediatric Health Care, ISSN 0891-5245, https://doi.org/10.1016/j.pedhc.2020.07.01

Tully, C., Aronow, L., Mackey, E., \& Streisand, R. (2016). Physical Activity in Youth With Type 1 Diabetes: a Review, 16(9). https://pubmed.ncbi.nlm.nih.gov/27475093/\#: :text=Youth\%20with\%20type\%201\%20diabetes\%20are\%20at\%20risk\%20for\%20d eveloping,as\%20for\%20good $\% 20$ glycemic $\% 20$

Unnikrishnan, R., Shah, V. N., \& Mohan, V. (2016). Challenges in diagnosis and management of diabetes in the young. Clinical Diabetes and Endocrinology, 2(1).doi:10.1186/s40842-016-0036-6

Vallesteros, F. D. J. A., Cachuela, C. J., Sanchez, A. A. Y., Santos, D. D. T., Aguba, P. K. V., \& Almario, J. C. C. (2019). Beyond Myself: A Phenomenological Study on the Financing Decision Deeds of Overseas Filipino Workers in Qatar.

Vallesteros, F. D. J. A., Dipasupil, P. A. E. B., Gamayon, R. A. V., Bautista, D. G. M., De Guzman, J. N. F., \& Milan, E. M. (2019). Leaving the Daylight: The Adjustments of Filipino Night Shift Workers in the State of Qatar.

Wee, B. V., \& Banister, D. (2015). How to Write a Literature Review Paper? Transport Reviews, 36(2), $278-288$. doi:10.1080/01441647.2015.1065456

White, F. (2016). The importance of parental involvement with the early years setting perspective of early years practitioners (Doctoral dissertation). Retrieved from https://research.thea.ie/handle/20.500.12065/2531

Wiebe, D. J., Berg, C. A., Mello, D., \& Kelly, C. S. (2018). Self- and social-regulation in type 1 diabetes management during late adolescence and emerging adulthood. Current Diabetes Reports, 18(5). doi:10.1007/s11892-018-0995-3

Wiebe, D. J., Helgeson, V., \& Berg, C. A. (2016). The social context of managing diabetes across the life span. American Psychologist, 71(7), 526-538. https://doi.org/10.1037/a0040355 
Xuereb, D., \& Xuereb, S. (2017). A school based study on the impact of Type 1 Diabetes Mellitus on the school life of children. Www.Um.Edu.Mt. Retrieved from https://www.um.edu.mt/library/oar/handle/123456789/25007

Yamada, S., Kabeya, Y., \& Noto, H. (2018). Dietary approaches for Japanese patients with diabetes: A systematic review. Nutrients, 10(8), 1080. doi:10.3390/nu10081080

Zappas, M. P., \& Granger, T. A. (2017). Managing adolescents with type 2 diabetes mellitus. The Journal for Nurse Practitioners, 13(4), e171-e176. doi:http://dx.doi.org.eres.qnl.qa/10.1016/j.nurpra.2016.11.020

Zuercher, J. L., \& Gopalan, C. (2020). Introducing physiology of diabetes to American Asian middle school and high school students. Advances in Physiology Education, 44(4), 587-591. https://doi.org/10.1152/advan.00088.2020 